\title{
Inculturation ou ethnicisation. Les pratiques religieuses des Pondichériens catholiques en Île-de- france
}

Brigitte Sébastia

\section{CpenEdition}

Journals

Édition électronique

URL : http://journals.openedition.org/assr/2778

DOI : $10.4000 /$ assr. 2778

ISSN : $1777-5825$

Éditeur

Éditions de l'EHESS

Édition imprimée

Date de publication : 1 juillet 2002

Pagination : 99-126

ISBN : 2-222-96721-X

ISSN : 0335-5985

Référence électronique

Brigitte Sébastia, «Inculturation ou ethnicisation. Les pratiques religieuses des Pondichériens catholiques en Île-de-france », Archives de sciences sociales des religions [En ligne], 119 | juillet septembre 2002, mis en ligne le 22 novembre 2005, consulté le 10 décembre 2020. URL : http:// journals.openedition.org/assr/2778; DOI : https://doi.org/10.4000/assr.2778 


\section{INCULTURATION OU ETHNICISATION LES PRATIQUES RELIGIEUSES DES PONDICHÉRIENS CATHOLIQUES EN ÎLE-DE-FRANCE (1)}

Les gestes rituels émaillant les messes organisées par la communauté pondichérienne de l'Île-de-France paraissent étranges aux yeux des fidèles accoutumés aux rites latins. Tout aussi insolite est la présence de ces Vierges de Velankaṇni (2) revêtues d'un sari doré ou de couleur, installées dans quelques paroisses franciliennes et qui peuvent faire l'objet d'une fête annuelle. Surprenante encore est la présentation d'une danse dévotionnelle indienne introduite dans la messe internationale de Lourdes lorsque la communauté pondichérienne y participe. Si ces gestes, ces rites, ces cantiques chantés en langue tamoule, ces statues mariales ou encore les objets utilisés dans la liturgie apparaissent comme des éléments exotiques en France, ils sont le produit d'efforts menés par l'épiscopat romain pour reconnaître la diversité culturelle de la communauté catholique.

Les nouvelles considérations de Rome sur l'importance de la valorisation de la pluralité culturelle au sein de la communauté catholique se dessinent dans les travaux du second Concile du Vatican: la constitution Sacrosanctum Concilum publiée le 4 décembre 1963 invite le clergé de chaque pays à utiliser la langue ver-

(1) Cet article s'est inspiré du mémoire de DEA de l'EHESS dirigé par Jean Pierre Albert que j'ai soutenu au Centre d'Anthropologie sociale de Toulouse en 1999 sous le titre : Les Pondichériens de l'île-de-France. Étude des pratiques sociales et religieuses. Grâce à une allocation de recherche attribuée par la DRAC de l'Île-de-France dans le cadre du patrimoine ethnologique, j'ai pu continuer l'étude de terrain entreprise depuis 1996 auprès des Pondichériens de l'Île-de-France de manière bien plus soutenue pendant l'année 1998-1999. Je remercie Jean-Pierre Albert et Catherine Clémentin-Ojha qui, par leurs remarques et leur soutien, ont contribué à la rédaction de cet article.

(2) Velankaṇni est un petit village tamoul situé sur la Côte de Coromandel à $10 \mathrm{~km}$ au sud de Nagappattinam où la Vierge y est apparue à trois reprises. Du fait que ce village soit situé au Tamil Nadu, les gens de cet État lui attribuent une identité tamoule qu'ils justifient par son aspect vestimentaire : elle est drapée d'un sari typiquement tamoul selon la manière adoptée par les femmes tamoules (le pan du sari est jeté sur l'épaule gauche) (SÉBASTIA, 1998). 
naculaire à la place du latin dans les rites liturgiques et à adapter la liturgie conformément aux normes stipulées par la constitution de la Sacrée liturgie «à la diversité des assemblées, des régions, des peuples, surtout dans les missions...» (SL 36-40, 119); la constitution Gaudium et Spes publiée le 7 décembre 1965 reconnaît la place de la culture au sein des sociétés et favorise son expression (GS 53-62); le décret Ad Gentes divinitus encourage le développement du clergé local notamment dans les jeunes Églises (nouvellement dotées d'un clergé indigène); celui-ci, à son tour, doit remplir la fonction de missionnaire auprès de son peuple : il doit propager le message chrétien et corriger les inégalités sociales et économiques (AM 16;22) (Concile acuménique Vatican II, 1967).

Ces constitutions et décrets ont des implications à deux niveaux : indigène et exogène. Par rapport au sujet abordé dans cet article, ceux-ci se traduisent : 1) par la nécessité d'acculturer l'Église catholique indienne (niveau indigène). Les catholiques de l'Inde ne doivent plus être considérés comme des étrangers dans leur pays. Ils partagent un ensemble de coutumes et de valeurs culturelles avec leurs frères hindous, musulmans, bouddhistes, jains ou sikhs. Il convient donc de tenir compte de cette culture commune (implicitement hindoue) pour favoriser l'expansion du christianisme et l'intégration des catholiques dans leur société plurielle; 2) par l'utilité de promouvoir la richesse culturelle des communautés immigrées (niveau exogène) pour une meilleure intégration dans la communauté paroissiale et dans la société d'accueil. Ainsi, les rites pratiqués par la communauté pondichérienne installée en Île-de-France sont en cohérence avec la volonté de l'épiscopat. Cependant, si on s'intéresse aux pratiques religieuses des autres ethnies catholiques établies en France, on constate d'une part que la liturgie reste largement dominée par les rites latins, et d'autre part que la présence de statues de saints ou de Vierges «communautaires» dans les églises est, mis à part Notre Dame de Fatima, exceptionnelle. Si on se tourne vers l'Inde et plus spécifiquement vers le Tamil Nadu, d'où est issue une importante proportion de la communauté pondichérienne, on constate également un important décalage par rapport à ce que l'on peut observer en France : peu d'occasions sont données de voir certains rites d'inculturation (3) pratiqués pendant la messe. La majorité des laïcs et des prêtres y est hostile. De nombreux Pondichériens installés en France manifestent aussi leur opposition à la

(3) Selon C. Clémentin-Ojha (1993, p. 110) : «(le néologisme «inculturation ») est apparu dans les propos des théologiens au début des années soixante (...). Le premier document pontifical à la (inculturation) mentionner (1977) la caractérise comme un processus visant à résorber le décalage entre foi chrétienne et culture, et à incarner le message chrétien dans les différentes aires socioculturelles. ». Le père LEgRAND de la Société des Missions Étrangères de Paris (MEP) (1993, p. 133) précise que : «... ce mot aurait fait partie du vocabulaire officiel des documents ecclésiastiques depuis le message du cinquième synode des évêques (1977). Il serait apparu dans le langage théologique, probablement sous la plume de P. J. Masson au début des années soixante, pour remplacer les termes adaptation ou accommodation, évidemment trop intrinsèques. » Enfin, le père Rossignol (MEP) pense que ce mot aurait été employé pour la première fois en 1959 au cours d'une semaine missiologique à Louvain en 1959 avant de s'imposer pendant le synode des évêques en 1974 et pendant la $32^{\mathrm{e}}$ Congrégation générale de la Compagnie de Jésus (1974-1975) (communication personnelle). Le terme se définit comme une acculturation à double sens : 1) Adaptation du message évangélique en tenant compte de la culture du pays concerné ; 2) Acclimatation du milieu culturel du pays confronté au message du Christ qui doit contribuer à enrichir la vision du monde propre à cette culture. 
pratique de ces rites. Certains, d'ailleurs, ont choisi de ne plus participer aux activités religieuses organisées par les «Communautés» pondichériennes (4).

S'intéresser à ces différences et à ces divergences apportera un éclairage sur l'utilisation de l'inculturation par la communauté pondichérienne dans la situation particulière de l'immigration.

\section{La communauté pondichérienne de France}

Les Pondichériens (5) installés en Île-de-France sont majoritairement des tamouls originaires des deux ex-comptoirs français enclavés dans l'État du Tamil Nadu. Ils proviennent essentiellement de Pondichéry et de ses aldées (6) et, dans une proportion bien plus faible, de la grande aldée de Karikal. Pondichéry était le siège politique et juridique des comptoirs français de l'Inde; elle était également le miroir de la culture française dispensée à travers l'enseignement. Les relations entre les indigènes et les pouvoirs colonial et ecclésiastique y étaient plus étroites (P. Bourdat, 1995; J. Weber, 1996; A.K. Neogy, 1997; W.F.S. Miles, 1995), de sorte qu'au moment de la rétrocession des territoires à l'Inde, les habitants de ce comptoir ont été plus motivés pour opter en faveur de la nationalité française. Ces caractéristiques expliquent la prédominance des natifs de Pondichéry de religion catholique résidant en France.

Les premières vagues des migrants pondichériens arrivent en France en 1956, date du Traité de cession, et plus intensément à partir de 1962, après la ratification du Traité (7). Le transfert de facto des possessions françaises à l'Inde s'accompagne d'une possibilité pour les habitants de choisir leur nationalité. Pendant une période de six mois, les ayants droit présents en Inde peuvent opter en faveur de la nationalité française, tandis que ceux qui sont absents la reçoivent de droit avec la

(4) Pour faire la différence avec la communauté dans sa globalité, j’emploierai cette graphie «Communauté » à chaque fois que ce terme s'appliquera à une partie de la communauté pondichérienne globale. Ainsi qu'il le sera précisé, une «Communauté » est un ensemble de membres qui s'organisent pour proposer des fêtes catholiques en tamoul à leurs compatriotes. Elle se compose d'un responsable, d'un chef de chorale et d'un groupe de personnes impliquées dans la chorale en tant que chanteurs ou instrumentalistes. À l'heure actuelle, il existe six "Communautés »: Paris, Pontoise, Mantes-la-Jolie, Trappes, Sarcelles, Évry-Grigny. Ajoutons que le lieu de résidence n'est pas toujours un critère d'appartenance à une «Communauté » déterminée, notamment lorsqu'il s'agit de celle de Paris.

(5) "Pondichérien » est une dénomination ambiguë car elle désigne aussi bien un habitant de la ville de Pondichéry qu'un habitant de l'Union Territory of Pondicherry composé aujourd'hui des ex-territoires français de Pondichéry, de Karikal, de Yanaon et de Mahé (Chandenagore a été rattaché à l'État du Bengale en 1951). Alors que les Pondichériens de la ville de Pondichéry et de ses aldées ainsi que ceux de l'aldée de Karikal appartiennent à l'aire culturelle tamoule, ceux de Yanaon parlent le telugu et ceux de Mahé le malayalam. Il existe en France des Pondichériens originaires de Yanaon et de Mahé mais ils sont peu nombreux et ne se mélangent pas aux Pondichériens tamouls.

(6) Le terme franco-pondichérien "aldée » qui désigne un territoire français en Inde composé d'une ville et d'un ensemble de villages et de hameaux est dérivé du mot portugais aldeia signifiant «village».

(7) Le traité de cession des Établissements français de Pondichéry, de Karikal, de Mahé et de Yanaon a été signé le 28 mai 1956. Le décret du traité a été publié dans le Journal Officiel du 23 octobre 1962 sous le numéro 62-1238 du 25 septembre 1962 (SÉBASTIA, 1999, op. cit., app.II, pp. 193-195). 
possibilité de la refuser (cas de nombreux militaires, d'agents administratifs ou de quelques étudiants qui étaient à cette époque dans les anciennes colonies, les DOM ou en métropole). Choix difficile, car celui-ci implique soit l'établissement en Inde, dont l'avenir est incertain, soit un départ pour la France. Mis à part ceux qui travaillaient dans les divers établissements français qui se sont maintenus après la rétrocession (Consulat, Institut français, écoles françaises), les Pondichériens de nationalité française ne pouvaient plus prétendre conserver leur emploi. Les premiers touchés ont été les fonctionnaires, puis, au fil du temps, les employés d'entreprises privées européennes rachetées par des entrepreneurs indiens.

La présence des Pondichériens en France s'accentue à partir des années 1973. Limités dans leurs perspectives par l'économie indienne alors que l'enrichissement de leurs compatriotes installés en France commence à se mesurer, de nombreux Pondichériens désireux de s'expatrier obtiennent la nationalité française en s'appuyant sur une faille du décret de cession des comptoirs (8). À la même période, ce sont les Pondichériens d'Hanoi et de Saigon qui arrivent en France, fuyant le Vietnam au moment du retrait des troupes américaines. Natifs ou descendants d'ancêtres nés à Pondichéry ou à Karikal, beaucoup se joignent aux Pondichériens de France avec lesquels ils partagent les coutumes, la religion catholique et, pour certains, la langue.

L'expatriation vers la France est toujours aussi convoitée. Malgré les restrictions imposées par la politique d'immigration française, des Pondichériens continuent de gagner la France par le biais du mariage, d'une bourse d'étude ou plus rarement d'un engagement militaire selon les possibilités inhérentes à leur nationalité. On estime aujourd'hui la population pondichérienne installée en France à plus de 50000 personnes (9) réparties entre les villes de l'Île-de-France et celles de garnison. Le lieu de résidence est souvent lié à la fonction professionnelle. Les militaires de carrière résident près de leur lieu d'affectation et le quittent lorsqu'ils sont mutés dans une autre caserne. D'autres se reconvertissent en postulant pour un emploi réservé dans une administration, ce qui les oblige souvent à s'installer en région parisienne. Les Pondichériens de l'Île-de-France occupent principalement des postes dans les administrations, quelques-uns, militaires de carrière, travaillent à la Défense. Le nombre important de reconversion dans le civil s'explique par un besoin de stabilité après des années passées à naviguer d'une ville à l'autre, voire d'un Territoire d'outre-mer à l'autre. Il trahit aussi les objectifs sous-jacents à l'engagement militaire comme moyen de financer le départ de l'Inde ou d'assurer la subsistance à l'arrivée en France. L'importance des militaires en activité, à la retraite ou reconvertis, mérite d'être soulignée en raison d'un effet inattendu: l'intégration du grade militaire dans les rapports de pouvoir entre les Pondichériens de l'Île-de-France. Le fait transparaît clairement dans leurs institutions religieuses

(8) Le décret avait omis de statuer sur le cas des descendants de Pondichériens nés hors des territoires français. Sur présentation du certificat de naissance attestant le lieu de naissance, des Pondichériens ont pu réintégrer la nationalité française. Ce système, qui a donné lieu à des abus avec achat de faux certificats de naissance, a néanmoins profité à de nombreuses personnes (DE COMARMOND, 1985 pp. 9 et sq.)

(9) Le dénombrement des Pondichériens en France est impossible du fait qu'ils possèdent la nationalité française. L'estimation de 50000 personnes m'a été fournie par J. Moudiappanadin, professeur de tamoul à l'INALCO, membre actif de plusieurs associations et de groupes de réflexion sur l'immigration tamoule, interprète des Sri Lankais auprès des organismes d'État et des services sociaux (1993). 
(aumônerie, "Communautés ») où la position dominante et la reconnaissance d'une personne sont déterminées par le grade militaire (10), les facteurs socio-économiques et la caste. La valeur accordée à chaque composante hiérarchique est variable, mais l'histoire de l'aumônerie et de la formation des "Communautés» montre que les deux facteurs non traditionnels prennent le pas sur la caste.

Schématiquement, les Pondichériens de France se partagent entre «bonnes castes» (vella lar , mutaliyă $r$, vanniyar) et intouchables (paraiya $r$, pallar). Les «bonnes castes » de l'Inde du Sud appartiennent au quatrième varna (sk) (11), grande catégorie de la société brahmanique, celle des śúdra (sk) composée de personnes nées pour servir les trois varna supérieurs. Du fait de la quasi-absence des varṇa intermédiaires en Inde du Sud (ksatriya, vaiśya; sk), elles occupent une place dominante dans la stratification sociale et maintiennent une forte distance avec les intouchables, ces avarna (sk) les plus discriminés du système des castes. À Pondichéry, cette dichotomie śúdra / avarṇa s'exprime par une résidence dans des quartiers séparés possédant leur propre lieu de culte hindou ou chrétien. En France, cette distance entre «bonnes castes» et intouchables ne transparaît pas aussi clairement, mais n'en existe pas moins, surtout lorsqu'il s'agit de chercher des alliés pour sceller les mariages.

\section{Genèse des célébrations catholiques des Pondichériens de France}

Les activités religieuses communautaires des Pondichériens catholiques de l'Île-de-France d'origine récente sont entièrement encadrées par l'institution ecclésiale. Elles découlent d'une part de textes épiscopaux en faveur des communautés migrantes, et d'autre part de la mise en place d'une aumônerie indienne créée en 1981.

\section{Les textes épiscopaux en faveur des migrants}

La fondation des aumôneries s'inscrit dans les perspectives de l'Église catholique soucieuse d'apporter son aide aux communautés chrétiennes déplacées de leur pays d'origine. Le migrant est un citoyen du Monde et en tant que tel il a le droit de

(10) Le chef de chorale de la «Communauté» pondichérienne de Paris est un lieutenant-colonel qui occupe un poste au Ministère de la Défense. Muté en 1998 pour deux ans en Belgique, il s'est fait remplacer par un Pondichérien, major de grade, qui travaillait sous ses ordres. Celui-ci est de confession hindoue... Ce dernier, envoyé quelques mois après en mission à Sarajevo (février 1999), désigna sous l'ordre du lieutenant-colonel un autre compatriote, cette fois-ci, catholique. Ce dernier est un civil, mais il occupe une fonction subalterne au major. Par ces choix qui correspondent à la hiérarchie militaire, le lieutenant-colonel est assuré de détenir l'autorité sur le groupe de chorale qu'il contrôle à distance, et de retrouver la place à son retour.

(11) Dans ce texte, j'utiliserai essentiellement des mots tamouls ou la forme «tamoulisée » du mot sanskrit; les termes sanskrits seront distingués par (sk). 
se rendre à l'étranger et de s'y fixer («Pacem in terris», DC, 1398, 1963). Qu'il soit arrivé pour des raisons économiques, politiques ou idéologiques, le migrant, dans la vie quotidienne, est exploité, rejeté, il revient donc à la communauté chrétienne de l'accueillir, de lui offrir un espace dans lequel il puisse communiquer dans sa langue et trouver du réconfort auprès d'un prêtre de même culture. C'est dans cet esprit que Pie XII publie le 30 septembre 1952 le texte fondateur des aumôneries ethniques, Exsul familia, dans lequel il stipule la nouvelle juridiction de la Sacrée Congrégation Consistoriale pour les migrants. Celle-ci doit être attentive à doter les communautés migrantes de prêtres de même origine linguistique en facilitant leur émigration. Elle doit veiller à leur installation dans le pays d'accueil et au bon fonctionnement de leur ministère. Ces aumôniers ou missionnaires des migrants nommés par leur évêque ont fonction de promouvoir le bien-être spirituel des migrants.

Dans un Motu proprio "Pastoralis migratorum cura» promulguant les nouvelles normes sur la pastorale des migrants, Paul VI insiste sur la nécessité de tenir compte du patrimoine spirituel et de la culture propre aux migrants pour que la pastorale puisse s'exercer de façon efficace :

«Les migrants emportent avec eux leur façon de penser, leur langue, leur culture, leur religion. Tout cela constitue un patrimoine spirituel de pensées, de traditions et de culture qui se maintiendra également en dehors de leur patrie.» $(D C, 1555,1970)$.

La prise en compte de la diversité culturelle des migrants s'accentue avec Jean-Paul II (DC 1906, 1985). L’Église catholique, de plus en plus présente dans les dossiers touchant l'immigration, se donne le rôle de médiateur entre les instances politiques et les migrants. Elle s'y applique par le biais d'associations ou de commissions inter-diocésaines dont la Pastorale des migrants. Outre les interventions pour dénoncer les réglementations limitant l'immigration, la situation des réfugiés et des clandestins, la xénophobie, la discrimination raciale, les instances religieuses s'élèvent contre une certaine "ghettoïsation» des nouveaux arrivants et les abus en matière d'assimilation forcée pratiqués par les États $(D C, 2190,1998)$.

La politique de l'Église catholique s'oppose totalement à l'idéologie républicaine française qui, de son côté, penche pour une totale assimilation culturelle des migrants. Concernant les Pondichériens, l'idéologie de l'Église a permis la valorisation de leur identité tamoule alors que la politique républicaine appliquée dans les territoires français de l'Inde (Weber, 1996) comme en France a été d'imposer le modèle culturel français.

Il est important de souligner que les Pondichériens sont encore très sensibilisés aux discours sur la valorisation de l'identité tamoule qui ont marqué les mouvements dravidiens pendant une grande partie du $\mathrm{XX}^{\mathrm{e}}$ siècle (12). Les réminiscences

(12) L'aire «dravidienne» est aujourd'hui composée de quatre États découpés à la fin des années soixante selon la langue dravidienne dominante: Karnataka, le kannada; Andra Pradesh, le telugu; Kerala, malayalam; Tamil Nadu, tamoul. L'aire «dravidienne » a subi fortement l'influence «indoeuropéenne », notamment à travers l'installation des brahmanes au XIe siècle fuyant les régions du Nord de l'Inde islamisées. Cette implantation a développé le système de caste, a influencé la littérature et la culture, a sanskritisé le registre religieux et les langues. Au début du siècle, quelques personnes influentes de langue tamoule ont lancé des mouvements contre l'hégémonie des brahmanes (le pouvoir britannique avait nettement favorisé leur promotion) et la domination culturelle des «Aryens ». L'exaltation de la culture et de la langue tamoule «désanskritisée » ont servi de fer de lance aux mouvements identitaires dravidiens (HARDGRAVE, 1965 ; DiRKS, 1996 ; JAYAKUMAR, 1999). 
des discours exaltant la supériorité culturelle des «Dravidiens» - entendons Tamouls - sur les «Aryens » apparaissent, dès lors qu'ils veulent justifier la nécessité de conserver et de transmettre la langue et la culture tamoule à leurs enfants. L'ancrage d'une conscience identitaire dans l'histoire renforce indéniablement l'importance attribuée à cette identité dans une situation de migration. C'est ainsi que prend sens le fort sentiment identitaire qui émane des discours des Pondichériens installés en France.

La différence idéologique entre la valorisation culturelle portée par l'Église depuis Vatican II et celle des principes égalitaires prônés par la République française induit un partage de la communauté pondichérienne de France en deux groupes : un qui adhère à l'idéologie ecclésiale et un autre qui se reconnaît dans les valeurs républicaines. Le premier est composé de «bonnes castes» tandis que le second est constitué d'intouchables et des élites de «bonnes castes». Cette différence se traduit, comme il sera précisé par la suite, par une forte représentation des «bonnes castes» de condition moyenne à la tête des «Communautés» pondichériennes.

\section{La création de l'aumônerie indienne : une institution bien singulière}

Jusqu'en 1981, les Tamouls indiens et sri lankais pouvaient consulter dans une pièce des MEP un prêtre-étudiant tamoul (13) et se réunir chaque mois dans la crypte de la chapelle des MEP pour assister à une messe célébrée en langue tamoule. Afin d'éviter que cette messe ne devienne l'unique activité religieuse des Tamouls et dans un souci de les maintenir dans leur paroisse d'affiliation, un père français des MEP crée alors une aumônerie indienne (14). Il en prend la direction et développe quelques offices religieux en langue tamoule dans les paroisses où sont concentrées les plus fortes communautés (Sarcelles, Gonesse, Gretz). Il organise ensuite deux messes annuelles en tamoul : une en décembre dans la chapelle de la Médaille Miraculeuse qu'il coordonne avec les sœurs de Saint-Vincent-de-Paul chargées du sanctuaire, l'autre au mois de juin à la basilique du Sacré-Cœur de

(13) La Société des Missions Étrangères de Paris, obligée d'abandonner sa vocation missionnaire dans les pays asiatiques devenus indépendants, offre aujourd'hui l'hébergement et le logement à une soixantaine de prêtres-étudiants du continent asiatique souhaitant préparer leur doctorat. Elle s'occupe de les inscrire à l'Institut catholique et à l'Alliance française et de les associer à une paroisse parisienne où ils exercent leur prêtrise à mi-temps. À leur retour en Inde, ces prêtres sont nommés en tant que professeur dans un séminaire. De nombreux représentants de l'épiscopat indien ont suivi ce cursus. Entre autres, on peut citer le cardinal Lurdusamy, Mgr M. Augustine, archevêque du diocèse de Pondichéry-Cuddalore. D'autres ont participé ou participent aux travaux sur l'inculturation tels que D.S. Amalorpavadass, ex-directeur du National Biblical Catechetical Liturgical Centre de Bangalore (NBCLC).

(14) Bien que l'aumônerie soit dénommée «aumônerie indienne», elle a surtout été fondée pour servir les Tamouls pondichériens et sri lankais. Il existe néanmoins un prêtre-étudiant keralais qui s'occupe des Pondichériens de Mahé et du Kerala. Chaque mois de février, cette communauté honore le père Agnelo, un missionnaire béatifié au début du siècle, dans l'église du Saint-Esprit (Paris XII ${ }^{\mathrm{e}}$ ). Depuis quelques années, la chorale de la «Communauté» pondichérienne de Paris participe à cette fête. 
Montmartre qu'il institue pour la première fois en juin 1983 en l'honneur de la visite de l'archevêque de Pondichéry (15). Au moment de son départ en retraite en 1985, il plaide auprès de la Commission épiscopale des migrations en faveur de la nomination d'un prêtre tamoul à la fonction d'aumônier.

Le père français se targue de n'avoir jamais rencontré de difficultés pendant son ministère auprès des Tamouls, si ce n'est pour introduire les traits d'inculturation dans la liturgie approuvés par la commission épiscopale auxquels ils étaient opposés. De plus, les Pondichériens qui, pourtant, l'ont bien connu, le mentionnent rarement, bien qu'il ait été l'architecte de l'aumônerie indienne, et attribuent la fondation de cette institution au premier prêtre tamoul recruté dans le diocèse de Pondichéry. L'absence de conflits durant son ministère tout comme la dénégation de son rôle dans l'histoire de l'aumônerie prennent sens en relation avec l'image de son passé missionnaire. En Inde, bien que le missionnaire ait inspiré la crainte et le respect, sentiments qui perdurent aujourd'hui dans les rapports entre les fidèles et le clergé indigène, il devait faire preuve d'une certaine flexibilité vis-à-vis des exigences de ses ouailles s'il ne voulait pas les perdre. En France, la situation n'est plus la même : ce sont les Pondichériens qui sont contraints de se plier aux règles du missionnaire et de la société d'accueil. Aussi, dès lors que l'aumônerie est administrée par un prêtre indien, la communauté pondichérienne se retrouve dans un contexte favorable à l'expression du prestige, de la hiérarchie, des règles de préséances. Pour appréhender le développement des conflits qui se sont produits à l'aumônerie, il est nécessaire de préciser l'utilisation du religieux dans la construction du statut hiérarchique d'une caste en Inde.

En Inde, la sphère religieuse domine tous les domaines de la vie sociale, politique ou économique. Les pouvoirs politique et économique ont besoin des instances religieuses pour être légitimés. Aussi, une caste qui, par sa position économique, cherche à asseoir son pouvoir politique ou sa domination sur les autres groupes en présence, doit s'impliquer dans des activités religieuses : offrir des repas au cours d'une célébration; financer une fête, un temple, une chapelle; offrir des terres ou des dons importants, etc.. Ce modèle de construction ou de légitimation du statut hiérarchique concerne également les chrétiens par le fait même

(15) La dévotion à la Vierge de la Médaille Miraculeuse n'est pas répandue en Inde mais elle a gagné le cœur des Pondichériens de l'Île-de-France qui, par leur sensibilité religieuse «panindienne», sont très attirés par les phénomènes miraculeux. En revanche, la dévotion au Sacré-Cœur est très répandue en Inde du Sud. À leur retour en Inde après 40 années de suppression de leur Compagnie et surtout à la fin du XIX ${ }^{\mathrm{e}}$ avec la consécration solennelle de l'univers au Sacré-Cœur par Léon XIII, les jésuites ont placé leur nouvelle mission du Madurai sous la protection du Sacré-Cœur. À Pondichéry, le Sacré-Cœur est l'église des intouchables par excellence car celle-ci a été édifiée dans leur quartier. Le jour de l'inauguration, les «bonnes castes » ont tenté de s'approprier l'église en interdisant l'accès de la nef aux intouchables. Échouant, ils se sont vengés en interdisant l'accès de Notre-Dame de L'Immaculée Conception de Nellitope aux intouchables. L'évêque de Pondichéry, Mgr Morel (MEP) par crainte de perdre la chrétienté des «bonnes castes » a pris leur parti et déclara les nefs de l'église de Nellitope, de la cathédrale et du Sacré-Cœur interdites aux intouchables. Les intouchables bafoués dans leurs droits portèrent plainte auprès des instances politiques en France. Ils furent entendus par Victor Augagneur, ex-député socialiste et promoteur de l'application des «droits de l'homme» dans tous les territoires français. Aussi, les intouchables pondichériens ont-ils une dévotion toute particulière pour le Sacré-Cœur. Ils interprètent le cœur aimant et souffrant du Christ comme l'expression de ses sentiments de commisération à l'égard de la condition des intouchables. 
qu'ils ont conservé le système de caste après leur conversion (16). Un des moyens très prisés pour obtenir du prestige ou affirmer une position hiérarchique est que le prêtre accepte de célébrer une messe privée et/ou de partager le repas familial. Dès l'arrivée des prêtres tamouls à l'aumônerie, ce schéma de légitimation s'impose. Il transforme les relations entre les Pondichériens fréquentant l'aumônerie en les hiérarchisant et cette hiérarchisation de plus en plus aiguë crée un contexte favorable au développement des "fêtes communautaires» autour de la Vierge de Velankannịi et à l'introduction des rites d'inculturation.

Parmi les prêtres tamouls qui ont administré l'aumônerie indienne, deux figures s'illustrent par leur inclination à manipuler les schémas hiérarchiques et à «indianiser» les pratiques catholiques des Pondichériens de l'Île-de-France.

Le premier de ces aumôniers (1985-1989) appartient à la caste dominante des vella lar. Saisissant l'opportunité, quelques familles de «bonne caste» de Paris revendiquent et obtiennent une position privilégiée au sein de l'aumônerie. Elles font également pression pour qu'il abandonne la charge de la chrétienté sri lankaise, de sorte que l'«aumônerie indienne» devient implicitement l'«aumônerie pondichérienne» (17). Dans cette nouvelle configuration, un événement singulier, dont l'impact sera considérable par la suite, se présente : au cours d'une messe mensuelle à Sarcelles, une Pondichérienne explique à l'aumônier que le curé de la paroisse Jean XXIII refuse d'installer une statue de la Vierge de Velankanni qu'elle a achetée au sanctuaire en remerciement de la guérison de son époux victime d'un arrêt cardiaque. L'aumônier propose à la famille d'installer la statue dans une pièce attenante à l'aumônerie et de l'offrir à la dévotion des Pondichériens. La famille (caste intouchable) s'incline mais son assentiment lui vaudra d'en être totalement dépossédée au profit des familles dominantes qui se l'approprient. Selon la conception indienne, toute divinité installée doit être honorée d'une fête annuelle commémorant le jour-fondateur. Cette statue est donc l'occasion d'organiser des festivités communautaires dans lesquelles les familles dominantes se réservent les marques de préséance qui devraient normalement être détenues par l'initiateur du culte (établissement de liens privilégiés avec l'aumônier, organisation de la fête, habillage de la statue et décoration du char et de l'église, offrande de nourritures en fin de céré-

(16) Les chrétiens indiens doivent la conservation du système de caste à Roberto de Nobili, un jésuite de la noblesse italienne (1577-1656). Ses idées comme sa manière de vivre calquée sur celle des brahmanes renonçants ont soulevé de vives oppositions dans le milieu missionnaire qui lui ont valu d'être dénoncé au pape. Ses bonnes dispositions vis-à-vis des règles inhérentes à la caste ont été parmi les points les plus décriés. Tout en démontrant la nature sociale du système de caste, R. de Nobili justifia l'importance de respecter ses règles pour favoriser les conversions (CLÉMENTIN-OJHA, 1998 ; ZUPANOV, 1999). Le pape Grégoire XV se prononça en sa faveur dans la bulle Romanae sedis antistes du 31 janvier 1623 (DE NoBILI, 1931; Bertrand, 1848, app. tome III)

(17) En plus de les administrer, l'aumônier avait organisé, dans une pièce attenante à l'aumônerie, le stockage de denrées alimentaires et de produits de première nécessité destinés aux réfugiés sri lankais. C'est surtout à cause de cette activité caritative que les Pondichériens ont évincé les Sri Lankais. Le pèlerinage de Lourdes des Tamouls a connu une fracture semblable, de sorte que depuis 1995, il existe deux pèlerinages distincts : celui des Pondichériens; celui des Sri Lankais. Après une période de semi-abandon (c'est une sœur du SITI, Service Inter-diocésain des Travailleurs Immigrés chargée de la communauté philippine qui était désignée pour s'occuper d'eux), les Sri Lankais ont reçu leur premier aumônier en 1995. Il possède une pièce dépendante de la paroisse Saint-Joseph-des-Nations située dans le $\mathrm{XI}^{\mathrm{e}}$ arrondissement de Paris. 
monie). La fête instituée en mai, mois de la Vierge, est célébrée chaque année à la même période dans les jardins des MEP.

Les familles dominantes au sein de l'aumônerie sont des familles de militaires issues des «bonnes castes». Elles se hiérarchisent selon deux critères non traditionnels : le statut socio-économique et le grade militaire. Cependant, une famille s'écarte de ce profil car elle est de caste intouchable mais son grade militaire et sa situation socio-économique hors du commun lui ont, malgré tout, permis d'être reconnue. La position ainsi acquise lui a ouvert la voie pour prendre la direction de la «Communauté » pondichérienne de Paris.

Après le départ de l'aumônier remplacé par quelques prêtres-étudiants plus préoccupés par leurs études que par le ministère de la communauté pondichérienne, l'aumônerie indienne s'écarte de sa fonction religieuse pour prendre les allures d'une association. Les familles dominantes multiplient les festivités culturelles, joignant à leur fonction d'organiser des activités religieuses celle de promouvoir l'identité tamoule. L'intervention du Père Rossignol des MEP (ancien missionnaire au Tamil Nadu) pour remettre de l'ordre s'est soldée par le retrait de quelques familles dominantes; celles-ci ont rapidement été remplacées par quelques autres en quête de prestige.

Le second aumônier (1992-1997) appartient aussi à une «bonne caste». Sa stratégie pastorale, complètement différente de celle de son prédécesseur, s'est traduite par une accentuation des rivalités de pouvoir. Celles-ci ne sont plus exprimées à l'intérieur d'une communauté unique, mais entre les divers groupes formés au cours de son ministère. Dans l'impossibilité d'affirmer son autorité sur l'aumônerie à cause des familles dominantes, il profite de dispositions particulières pour fonder la «Communauté» pondichérienne de Pontoise. Une messe mensuelle en tamoul instituée dans la paroisse de Notre-Dame de Pontoise lui donne l'occasion d'établir des contacts avec les Pondichériens qui fréquentent cette paroisse. Il les invite à former une chorale et intercède auprès du prêtre de la paroisse de Notre-Dame de Pontoise pour obtenir l'autorisation d'installer dans l'église une statue de la Vierge de Velankaṇni. En agissant ainsi, l'aumônier ne cache pas ses intentions de concurrencer les Pondichériens qui contrôlent les fêtes religieuses de l'aumônerie indienne. Et cela se vérifie par la multiplication des «Communautés» pondichériennes qui ont vu le jour à cette même période. Les «Communautés» de Mantes-la-jolie et d'Évry-Grigny prennent naissance lorsque l'aumônier, à la demande de familles, institue une messe tamoule, celle de Trappes est dotée de quatre messes célébrées à des occasions particulières (Saint-Joseph en mars; Sacré-Cœur en juin; Vierge de Velankaṇni en octobre; fête des morts en novembre). Enfin, il favorise la constitution de la «Communauté» de Sarcelles en l'incitant à former une chorale pour accompagner les messes mensuelles mises en place par le fondateur de l'aumônerie, fonction qui était détenue jusque-là par la «Communauté » de Paris. Privilégiant la «Communauté» de Pontoise dont il est le fondateur, il utilise ses relations avec les organisateurs de la "Communauté» pour légitimer son autorité et promouvoir les innovations. Ainsi, il attribue à la «Communauté» de Pontoise la vocation honorable de servir d'exemple à toutes les autres «Communautés».

À la fin de son apostolat à l'aumônerie, la communauté pondichérienne est devenue plurielle, fragmentée en six «Communautés». Cet éclatement, il va sans dire, n'est jamais présenté comme tel, mais comme un moyen de doter chaque 
groupe d'une messe tamoule afin d'éviter les déplacements à Paris. Seulement, les faits comme les paroles trahissent une émulation qu'il est difficile d'ignorer. Chacune de ces «Communautés» utilise un schéma identique : messe tamoule, chorale, installation de statue de la Vierge de Velankanni dans l'intention de célébrer une fête communautaire (les «Communautés» de Grigny et de Sarcelles n'ont pas reçu l'assentiment des prêtres paroissiaux pour installer leur Vierge). De plus, on remarque la nette prédominance des «bonnes castes» parmi les deux membres responsables de chacune des six «Communautés», le chef de chorale et le représentant communautaire, à l'exception de Paris, évoquée précédemment, où le représentant est un intouchable, et de Pontoise où le chef de chorale est également un intouchable. Le statut de ce dernier qui ne possède ni un grade militaire honorable ni un profil économique élevé, est justifiable par le rôle que cet homme a joué dans la formation de sa "Communauté». En tant que guitariste, c'est à lui que l'aumônier s'est adressé pour mettre en place la chorale et c'est également lui qui, en rapportant la statue de la Vierge de Velankanni, a favorisé la création de la fête mariale. Ainsi, il a permis à l'aumônier d'atteindre ses objectifs : concurrencer la «Communauté» de Paris et faire accepter ses innovations.

\section{Caractéristiques des célébrations religieuses pondichériennes}

L'origine des fêtes religieuses organisées par la communauté catholique pondichérienne est diverse. Dans la plupart des cas, elles relèvent de la volonté conjuguée de l'aumônier et d'une «Communauté» particulière. Les jeux de pouvoir au sein de l'aumônerie et la fragmentation de la communauté pondichérienne se sont traduits quelquefois par l'arrêt d'une célébration ou d'une activité religieuse. Cela a été le cas de la messe tamoule célébrée annuellement à Notre-Dame de Paris ou encore des émissions en langue tamoule diffusées sur Radio Notre-Dame. Mais, de manière générale, ils ont eu des effets dynamisants par la multiplication des activités religieuses qu'ils ont suscitée. Aujourd'hui, la communauté pondichérienne de l'Île-de-France possède cinq messes tamoules mensuelles célébrées dans cinq paroisses de la région parisienne (Sarcelles, Grigny, Paris, Mantes-la-Jolie, Pontoise), quatre célébrations annuelles spéciales (Porikal (18), Sacré-Cœur à Montmartre, fête de l'amitié uravu vila, Notre-Dame de la Médaille Miraculeuse), un pèlerinage officiel à Lourdes, et surtout, six fêtes en l'honneur de la Vierge de

(18) Le Porikal est une fête hindoue qui célèbre les moissons au début du mois tamoul tai (mijanvier-mi-février). À cette occasion, les Tamouls font cuire à gros bouillons du riz dans du lait sucré et arômatisé que l'on appelle poinkal. Le fort bouillonnement qui métaphorise la prospérité est une manière d'influencer les futures récoltes (définitions du rituel : Dumont, 1992, Good, 1983). Cette fête, ainsi que plusieurs autres (fête de la République de l'Inde, fête de l'Indépendance de l'Inde, fête de la lumière Tipāvali, fête des outils Sarașvati pücai) ont été introduites dans le calendrier chrétien indien au cours d'une Conférence des évêques catholiques de l'Inde tenue en 1972. En France, la fête de Poìkal est organisée par la «Communauté» pondichérienne de Paris et c'est la responsable de la «Communauté» qui se charge de préparer le pot de ponkkal. Ce plat, distribué après la messe aux participants, constitue un annatänam dont une des fonctions est de renforcer la position hiérarchique du donateur. Pendant la messe, le pot de poinkal est placé devant le maître-autel et il est béni en fin de célébration. 
Velankanni dont quatre de type communautaire (Paris, Pontoise, Mantes-la-Jolie, Trappes). À l'exception des messes mensuelles en tamoul dont la durée limitée à une heure ne permet pas la pratique de rites d'inculturation, toutes les célébrations communautaires annuelles en sont ponctuées. Il faut souligner que ces célébrations, du fait de l'usage exclusif de la langue tamoule, éveillent peu la curiosité des autres communautés ethniques de la paroisse. De ce fait, l'emploi de «fête communautaire» prend tout son sens, sens renforcé encore par la rareté des Tamouls sri lankais ainsi que celle des hindous (Tamouls sri lankais ou indiens) qui, dans les villages christianisés de l'Inde, forment une part non négligeable de l'effectif présent aux offices religieux. Ce chapitre va s'intéresser à définir les fonctions de la Vierge de Velankaṇi et des traits d'inculturation dans les pratiques religieuses des Pondichériens.

\section{La Vierge de Velankaṇni : la figure emblématique des Pondichériens}

Velankanni Mătā est considérée par les dévots du Tamil Nadu comme la Vierge du Tamil Nadu. C'est le petit village tamoul de Velankaṇni qu'elle a choisi pour répandre ses bienfaits en apparaissant à trois reprises, revêtue d'un sari tissé et porté selon la coutume du pays tamoul. Son culte, initié par les Portugais arrivés sur la Côte de Coromandel au début du XVII siècle, s'est développé au cours des siècles. Mère de la Bonne Santé ou Arokkiya Mata, cette Vierge thaumaturge connaît aujourd'hui un succès grandissant qui se traduit, au moment de sa fête patronale célébrée entre le 29 août et le 8 septembre, par l'afflux de pèlerins hindous et chrétiens venus de toutes régions de l'Inde (Sébastia, 1998). Les Pondichériens ont une vénération toute particulière pour cette figure mariale. Elle est installée sur tous les autels domestiques, elle est plaquée sur le mur au milieu des chromos ou illustre un calendrier. Quelle qu'en soit la forme, il est difficile de l'ignorer tant son image est omniprésente. Excepté dans la paroisse de Notre-Dame des Anges administrée encore aujourd'hui par des prêtres français des MEP opposés à ce culte qui éclipse les autres dévotions, toutes les églises de Pondichéry et des aldées possèdent une statue de la Vierge de Velankaṇni. Ce phénomène ne se rencontre pas dans les églises de l'aldée de Karikal car, résidant à une vingtaine de kilomètres de Velankaṇni, les Karikalais préfèrent se rendre auprès de la Vierge du sanctuaire originel.

Les Pondichériens de France ont conservé une grande foi en la Vierge de Velankaṇni qu'ils communiquent à leurs enfants à travers les séances de prières programmées le soir autour de l'autel domestique. Respectant la tradition, les activités religieuses familiales sont sous la responsabilité de la mère, gardienne du foyer et du bien-être de la famille, une fonction qu'elle prend soin de transmettre à ses filles. La Vierge de Velankanni est au cœur des prières chaque fois qu'un événement perturbe le bon déroulement de la vie familiale. Et les occasions ne manquent pas, on pourrait même affirmer qu'elles s'accentuent à mesure que les enfants grandissent. Les appréhensions liées à leurs études (échec scolaire, éducation française exacerbant l'individualisme, mauvaises fréquentations), au chômage, à la difficulté à leur conclure un mariage arrangé, sont autant de problèmes qui se surajoutent à la difficulté de vivre en France. Les femmes constituent la catégorie la plus fragilisée par cette situation. Parlant souvent peu ou pas le français, elles 
n'ont pas de vie extérieure et vivent confinées et esseulées dans leur appartement une grande partie de la journée. Cette situation ne concerne pas seulement les femmes des primo-arrivants, elle est sans cesse réactivée par les jeunes épouses qui arrivent du Tamil Nadu, essentiellement de Pondichéry. Elles sont souvent préférées à leurs sœurs de France pour des raisons diverses: soucis de conclure un mariage préférentiel (19), un mariage dans une famille alliée ou de même caste si celle-ci est faiblement représentée en France, d'obtenir une dot élevée ou une alliée de caste supérieure (la nationalité française est très prisée). Le choix peut découler aussi de 1'«imaginaire culturel»: une jeune fille éduquée en Inde sera une meilleure épouse car elle connaîtra la tradition et aura été élevée à l'abri de la culture occidentale. Suite à de tels mariages, il n'est pas rare que certaines subissent les sévices de leur époux et de leur belle-famille en raison d'une mésentente, d'une dot impayée, de l'absence de descendance mâle. À la différence de l'Inde où elles peuvent retourner chez leurs parents, en France cela devient impossible. Tout aussi difficile est le moment de la première maternité car si elles ne peuvent pas se rendre en Inde comme le veut la tradition (20), elles doivent gérer les problèmes elles-mêmes sans bénéficier de l'aide expérimentée de la mère.

Traditionnellement élevés dans un contexte familial et social qui privilégie le religieux, les Pondichériens accordent d'autant plus d'importance à l'espace religieux qu'il permet de trouver un peu de soutien pour faire face aux difficultés rencontrées dans la vie quotidienne en France. Ces difficultés de vivre en France favorisent les activités religieuses qui permettent de créer des liens communautaires, de retrouver une atmosphère indienne, d'établir des contacts pour les futures alliances des enfants, surtout des filles (21). Elles se traduisent également par le développement de statues de la Vierge de Velankaṇni installées dans les paroisses pour assurer la protection et le bien-être de la famille et de la communauté.

L'aumônerie indienne ainsi que dix paroisses dispersées en Île-de-France possèdent une image (22) de la Vierge de Velankaṇni. Parmi elles, quatre appartiennent à des «Communautés» pondichériennes et font l'objet d'une fête communautaire célébrée par l'aumônier tamoul, tandis que les autres ont été installées

(19) La parenté dravidienne privilégie les mariages entre cousins croisés (fille avec fils MB ou FZ). Les mariages entre oncle maternel-nièce (MyB-MD) lorsque les ego sont de même niveau d'âge, ne sont pas inexistants bien qu'ils tendent, comme en Inde, à se raréfier.

(20) Après les rites du septième mois de grossesse, le mari et quelques parents chargés d'offrandes accompagnent la jeune épouse chez ses parents. Elle y restera plusieurs mois après son accouchement afin de se rétablir (le temps de repos est fonction de la caste; cf. cas des kallar étudié par L. DuMONT, 1992).

(21) Le mariage des filles est un épineux problème. Du fait de la préférence pour des belles-filles de l'Inde et du peu d'attrait pour des gendres de l'Inde dû à des critères de nationalité, de langue, de niveau d'étude, d'emploi, le nombre des jeunes filles à marier ne cesse de s'accroître ainsi que leur âge. Ceci se traduit par des mariages mixtes - entendons franco-pondichérienne-franco-français - que les parents acceptent par la force des choses. Il faut convenir également que, par rapport à leurs frères, les jeunes Pondichériennes se montrent généralement moins soumises au choix de mariage imposé par leurs parents comme au modèle éducationnel.

(22) Il s'agit de dix statues de taille variable (par ordre d'arrivée : église des Bâconnets, Antony; Aumônerie tamoule; Saint-Jean-Baptiste, Mantes-la-Jolie; Notre-Dame, Pontoise; Saint-Georges, Trappes ; Saint-Martin, Orly ; Saint-Paul-Saint-Pierre, Sannois ; Basilique, Saint-Denis ; Notre-Dame des Cités, Viry-Châtillon; cathédrale Sainte-Geneviève, Nanterre) et d'une photographie à l'intérieur d'une niche (Notre-Dame de la Paix, Corbeil-Essonne; installée après celle d'Orly). 
individuellement. La plupart des statues sont le résultat d'une transaction votive (guérison, travail en France, bien être familial ou la manifestation d'une forte dévotion). Les propos que l'on rencontre de manière récurrente traduisent l'homologie culturelle entre la Vierge et les Pondichériens (Tamouls). Originaire du même pays, la Vierge est d'autant plus apte à les aider qu'elle connaît bien les difficultés des Tamouls. Comme eux, elle se retrouve en situation d'immigration, une autre analogie qui renforce le lien :

«On se sent proche d'elle comme quelqu'un de notre famille. Quand on a des problèmes, on peut aller à l'église et lui parler. On lui parle en tamoul et elle comprend nos problèmes car elle les connaît. Elle seule peut nous aider. C'est pour cela qu'on l'a installée dans l'église car elle peut aider aussi les autres familles pondichériennes qui habitent ici» (informateur de Corbeil-Essonne)

L'identification de la Vierge de Velankaṇni à la culture tamoule justifie que ce soit cette figure singulière que les Pondichériens privilégient lorsqu'ils veulent exprimer leur identité ou concurrencer une autre «Communauté». En Inde, lorsqu'une statue est installée, celle-ci doit recevoir un culte et être honorée une fois dans l'année, normalement, le jour anniversaire de son installation. Comme toutes les festivités religieuses indiennes, celles qui honorent une divinité développent les marques de préséance qui profitent à l'initiateur du culte. Dans cette perspective, installer une Vierge de Velankaṇni est une manière d'obtenir du prestige et la reconnaissance des dévots. Cette stratégie a été celle des "Communautés»pondichériennes de Mantes, de Pontoise et de Trappes. Pour des raisons diverses, ces dernières ont été autorisées à installer la statue dans leur paroisse mais toutes les «Communautés» n'ont pas eu cette chance et, de ce fait, elles se trouvent privées d'une possibilité d'organiser une «fête communautaire». Parmi les onze représentations de la Vierge de Velankaṇni recensées en région parisienne en 1999, six bénéficient d'une fête annuelle mise en place par une "Communauté» (Paris, Pontoise, Mantes, Trappes) ou par le curé d'une paroisse (Antony (23), Orly). Il faut souligner que les familles à l'origine des installations des Vierges de Velankaṇi dans la basilique de Saint-Denis, dans la cathédrale de Nanterre et dans l'église de Sannois manifestent fermement leur intention d'instituer, elles aussi, une fête communautaire. Mais pour l'instant, elles se heurtent au refus de l'actuel aumônier tamoul qui, face aux difficultés à gérer les rivalités entre les six «Communautés » existantes, rejette tout projet qui pourrait induire de nouvelles scissions.

Les enjeux autour des installations de Vierges de Velankaṇni, dans cette situation particulière d'immigration, attestent que cette représentation fonctionne comme un marqueur d'identité et une opératrice d'altérité. Ces deux fonctions justifient l'intérêt de certains Pondichériens pour l'introduction des traits d'inculturation dans la liturgie de leurs fêtes communautaires.

(23) La fête de la Vierge de Velankaṇni installée dans l'église des Bâconnets à Antony s'est transformée en «fête communautaire» depuis 1998 avec l'arrivée du nouvel aumônier. Précédemment, elle était célébrée pendant une messe dominicale par le prêtre de la paroisse à laquelle tous les fidèles, quelle que soit leur origine ethnique, participaient. 


\section{Les rites d'inculturation : décalages et controverses}

À côté des activités religieuses prises en charge par les «Communautés» pondichériennes, il existe quelques célébrations auxquelles des Pondichériens participent. Elles se démarquent des précédentes par la variété ethnique de l'assistance. Elles émergent lorsque un prêtre, souvent un religieux au passé missionnaire, sensibilisé au problème de l'intégration des communautés catholiques d'origine étrangère, invite les communautés ethniques les plus représentées dans sa paroisse à animer la messe selon la coutume de leur pays d'origine. C'est une manière de tenir compte de chaque culture, de la mettre en valeur et de faire découvrir «ce savoir-faire dévotionnel» aux autres paroissiens. Les objectifs sous-jacents à cette valorisation sont d'attirer les migrants au sein de l'Église catholique de France, point non négligeable si on tient compte de la forte religiosité de certaines communautés, et de favoriser les relations interethniques articulées sur le partage d'une identité religieuse commune. En bref, il s'agit de créer au sein de la paroisse une famille catholique, unique dans la foi, plurielle par la culture. Plusieurs groupes de Pondichériens affiliés aux paroisses d'Orly, de Saint-Denis ou encore d'Antony ont bénéficié de ces dispositions. La formation de la «Communauté» de Trappes découle également de l'invitation du prêtre paroissial à mettre en place une messe pondichérienne. Cette messe n'ayant pas été insérée dans le calendrier dominical comme pour les paroisses précédemment citées, sa mise en place a eu pour effet de favoriser la formation de la "Communauté» de Trappes et d'accentuer le caractère communautaire des célébrations qu'elle organise. L'invitation à mettre en scène la culture a rencontré un réel engouement auprès des Pondichériens qui ont vu l'opportunité de se valoriser à travers elle. En effet, à l'instar des messes organisées par les «Communautés» pondichériennes, toutes ces célébrations intègrent systématiquement des rites d'inculturation et ce, en dépit du fait qu'ils ne font pour ainsi dire jamais partie du modèle liturgique adopté en Inde.

Une telle contradiction sur la pratique des rites d'inculturation en France et en Inde est également au centre d'une autre manifestation religieuse à laquelle des Pondichériens participent. Cette fête observée en 1998 est d'autant plus intéressante qu'elle explicite les perspectives sous-jacentes à leur implication dans des activités religieuses paroissiales ou diocésaines.

La Commission épiscopale a favorisé les mouvements pastoraux au sein de chaque diocèse, une place toute particulière a été attribuée à la pastorale des migrants dont l'objectif est d'aider les immigrés à vivre au sein de la société française et de la communauté paroissiale. Dans ce cadre, chaque année les diocèses organisent une Fête des Migrants ou une Messe des Peuples dont les perspectives recoupent celles énoncées précédemment : stimuler l'intégration des immigrés et favoriser le dialogue entre les catholiques d'origines culturelles diverses. Les associations laïques et religieuses composées de Français de souche et d'immigrés sont également invitées à témoigner sur leur travail, à échanger leurs expériences, à dénoncer les discours xénophobes, à organiser des actions ponctuelles pour s'opposer aux projets de lois défavorisant l'immigration. Ces fêtes s'articulent entre un temps liturgique où chaque communauté participante est invitée à exprimer sa foi selon sa culture et un temps profane où des interventions d'associations laïques et religieuses et des spectacles présentés par chaque groupe ethnique sont programmés après le partage d'un repas mêlant les saveurs les plus variées. 
Les représentants de la «Communauté» d'Évry-Grigny n'ayant pu installer une Vierge de Velankaṇni et organiser une fête communautaire dans leur paroisse, sont fiers de souligner qu'ils font partie de la pastorale des migrants et, à ce titre, qu'ils s'associent aux autres ethnies pour organiser la «Fête des migrants» de leur diocèse. Dans les faits, on relève la nette prédominance des traits d'inculturation indiens tout au long de la messe alors même que six autres communautés originaires d'Afrique (Béninois, Maliens), d'Amérique (Antillais), d'Asie (Hmong) et d'Europe (Polonais, Portugais) y participent. Si les Pondichériens sont largement mis en scène tout au long de la célébration religieuse, en revanche, leur participation aux deux autres activités est nettement plus réduite : ils ne se mêlent pas aux autres communautés pour partager le repas qui, en principe, doit favoriser les échanges (mêts, idées, culture) et s'ils ne peuvent participer au spectacle comme cela a été le cas en 1998 du fait de l'indisponibilité de leur danseuse de pārati natam (sk bhārata natya), ils choisissent de s'éclipser. Ce comportement, en contradiction avec l'idéologie de la Fête des migrants révèle clairement que l'objectif de leur participation est centré sur l'opportunité d'exalter l'identité tamoule. De leur point de vue, la messe s'offre comme espace privilégié pour exalter l'identité : elle est pourvoyeuse de rites d'inculturation considérés comme porteurs d'une richesse culturelle, et par sa nature institutionnelle, elle sert de lieu de légitimation.

La comparaison du contenu des célébrations festives pondichériennes et notamment entre celles organisées par chacune des six «Communautés» pondichériennes permet de déceler quelques variantes intéressantes pour appréhender les rites d'inculturation dans leur fonction de marquer l'altérité. Le modèle-type liturgique se compose : de l'allumage d'une lampe ou kuttuvilakku (24) au commencement de la messe, celle-ci peut être posée au centre d'un dessin appelé kólam (25) si le prêtre paroissial le permet; d'un rite particulier appelé ârāti pratiqué à l'ouverture de la messe et à la célébration de l'Eucharistie; d'un cortège d'offrandes avant 1'Eucharistie. Lorsque ces messes honorent la Vierge de Velankaṇni d'une «Communauté » pondichérienne particulière (Paris, Pontoise, Mantes-la-Jolie, Trappes), la messe est suivie ou précédée d'une procession têr

(24) Le kuttuvilakku est une grande lampe sur pied composée d'un réceptacle pour contenir l'huile qui alimente cinq mèches de coton. Bien qu'il ait une origine hindoue, les catholiques l'ont adopté en substituant la croix au symbole hindou (cygne, paon, forme phallique). Allumé, il a fonction de placer une cérémonie religieuse sous les bons auspices. Aussi, il est commun de trouver des kuttuvilakku devant le maître-autel ou en face de la statue la plus vénérée d'un sanctuaire chrétien. Il est aussi prégnant dans les foyers indiens en Inde comme en France où il est allumé lors des importantes cérémonies religieuses ou domestiques.

(25) Le kölam est une tradition du sud de l'Inde. Il consiste en un dessin tracé sur le sol avec de la poudre de riz blanche. Il a une fonction faste. Chaque matin, après la purification du sol, les femmes esquissent un kōlam sur le seuil de leur maison; elles le renouvellent le soir si une divinité portée en procession doit les visiter. Les autels domestiques sont aussi décorés d'un kōlam réalisé quelquefois avec de la peinture. Les jours où une cérémonie faste doit se dérouler (mariage, nubilité, $7 \mathrm{e}$ mois de grossesse, dation du nom), les femmes élaborent de plus beaux dessins utilisant quelques symboles de prospérité. En France où il n'est pas toujours possible de dessiner sur le sol, il n'est pas rare de trouver devant les autels domestiques, un tapis présentant des figures géométriques évoquant les kōam. Celui posé devant la statue de la Vierge de Velankaṇni installée dans l'église Saint-Pierre-Saint-Paul de Sannois en est un exemple. 
vila (26) et les festivités s'achèvent par l'offrande de quelques sucreries ou d'un repas plus consistant annatānam (27). Parmi ces phases rituelles, le rite d'āräti est celui qui soulève le plus de controverses chez les catholiques tamouls d'Inde et de France.

En Inde du Sud, en dehors des centres catholiques tels que les ashrams, certains couvents ou séminaires et bien sûr, des centres spécialisés dans les travaux d'inculturation tels que celui de Tindivanam (formation de catéchistes) ou le NBCLC de Bangalore (études sur la Bible, le catéchisme, la liturgie), l'ārāti n'est pratiqué que très exceptionnellement (28). Pourtant, ce rite a été défini dès les premiers travaux sur l'inculturation développés par le Centre national de liturgie fondé au cours de la Conférence des Évêques Catholiques de l'Inde CBCI en 1966. Il fait partie des douze points d'inculturation approuvés par la majorité des évêques de l'Inde et présentés à la Commission épiscopale de la liturgie de Rome. Cette dernière s'est prononcée en leur faveur le 25 avril 1969. La place et la définition du rite d'ārâti sont stipulées par les points 10 et 12 du texte:

10 - Le rite préparatoire de la messe pourra inclure : a/ la préparation des dons; b/ l'accueil du célébrant à la manière indienne, c'est-à-dire avec un simple ârâti au moment de l'ablution des mains; c/ l'allumage de la lampe; d/ le don de la paix entre les fidèles en signe de réconciliation mutuelle.

12 - Dans le rite de l'Offertoire, à la conclusion de l'anaphore, la forme indienne de dévotion pourra être intégrée, c'est-à-dire par un double ou triple $\bar{a} r \bar{a} t i$ de fleurs et/ou d'encens et/ou de lumière (29).

(26) Le circuit de la procession est un facteur non négligeable dans la construction de la notoriété d'une fête pondichérienne en Île-de-France. L'église de Mantes-la-Jolie étant située dans le quartier du Val-Fourré composé essentiellement d'une population turque, la "Communauté » pondichérienne n'a pas eu le droit d'organiser sa procession mariale à l'extérieur de l'édifice. Devant le choix des fêtes de la Vierge Velankaṇịi proposé à cette même période, des Pondichériens préfèrent assister à des cérémonies «plus grandioses » comme celle de Pontoise. La procession organisée à Pontoise est le modèle opposé au précédent. Le trajet processionnel s’inscrit dans un carré formé par quatre rues («les quatre rues du char» selon le modèle hindou de préséance) et le déroulement de la procession est protégé par la police municipale qui règle la circulation. La présence de la police qui est rétribuée pour son intervention, a aussi un rôle dans la légitimation de la fête, car en Inde, l'ouverture d'une fête hindoue ou catholique importante impose toujours la présence des instances civiles telles que le tashildar, le chairman, le Village Administrative Officer, le surintendant de la police.

(27) Le «don de nourriture» est effectué dans le but d'accomplir une promesse vis-à-vis d'une divinité en échange ou dans l'intention d'un vœu. Il s'inscrit également dans une problématique de préséance et de valorisation d'une position hiérarchique; c'est essentiellement pour cette fonction qu'il est effectué en France.

(28) En Inde, je n'ai observé la pratique de l'ārāti que dans la messe du 15 août à Nellitope (ville attenante à Pondichéry) où était célébrée conjointement les fêtes de l'Assomption de la Vierge et l'Indépendance de l'Inde. L'ärăti était présenté au moment de l'Eucharistie par six petites filles revêtues chacune d'une des trois couleurs du drapeau national indien (vert-blanc-safran).

(29) Le texte complet est en français dans l'article de Puthanangany (1983, pp. 115-124) ou en anglais dans l'ouvrage de AmALORPAVADASS (non daté, pp. 31 et sq.). Les autres points du texte concernent la posture et l'habillement du prêtre : position assise sur le sol, retrait des chaussures pendant l'office religieux, port d'une chasuble en forme de tunique et d'une étole; les gestes dévotionnels : inclinations et añjali hasta (sk; mains jointes placées au-dessus du front) pour remplacer la génuflexion, pañcāinga (sk; position d'obéissance exprimée avec cinq composants du corps : bras, genoux, tête, voix, regard) comme rite pénitentiel, attouchement des objets sacrés suivi de l'apposition sur les yeux ou le front pour remplacer le baisement (éviter la «pollution» de la salive), añjali hasta au moment du baiser de la paix ; les objets et les substances liturgiques : accentuation de l'utilisation de l'encens, la forme de l'encensoir, l'utilisation d'un plateau en tant que Corporal, celle de la lampe à huile à la place des cierges. 
La constance dans le choix des rites d'ārāti en France pour célébrer les messes pondichériennes selon la «coutume du pays» est pour le moins contradictoire avec la réalité indienne. En même temps, ce choix peut être légitimé par la permanence de cette pratique rituelle dans la sphère domestique. Il convient de décrire ce rite selon sa forme religieuse hindoue et sa forme sociale pour le comparer avec sa pratique dans le catholicisme.

Au cours du culte de l'image divine hindoue, ou $p \bar{u} c a i$, le prêtre offre à chaque divinité du temple des lampes de camphre et un plateau contenant des ingrédients spécifiques (cendres sacrées, santal, vermillon, camphre allumé) qu'il présente en leur faisant décrire trois rotations dans l'espace. Cette gestuelle a la double fonction de préserver chaque divinité du mauvais œil et de la nourrir des offrandes, étant entendu que les divinités hindoues possèdent une humanité. À la fin de ce rituel, le prêtre distribue ces offrandes consacrées aux dévots; les fidèles les reçoivent en tant que piracotam ou «restes du repas divin». Le prêtre présente les lampes de camphre sur lesquelles les dévots apposent les mains avant de les porter à leurs yeux et sur leur tête, puis leur distribue les cendres, le vermillon, le santal qu'ils appliquent au milieu de leur front

Dans l'espace domestique, le rite d'ārāti est inhérent à toutes les cérémonies fastes honorant un hôte exceptionnel, un parent particulier, de nouveaux mariés, une jeune fille nubile, un jeune enfant, etc.. Selon la conception hindoue, chaque être humain contient en lui une parcelle du divin, les rites pour l'honorer sont alors calqués sur ceux destinés aux divinités. Dans ce cas, ce sont les femmes fastes (non veuves ou non polluées temporairement par un deuil, des menstrues, un accouchement), choisies selon les règles de parenté, qui pratiquent ce rite avec un plateau similaire à celui utilisé dans le $p \bar{u} c a i$ d'où elle puise le vermillon et le santal pour marquer le front des destinataires du rite.

Dans le catholicisme indien, les ārâti autorisés par la commission liturgique romaine sont pratiqués à deux moments précis de la messe : au commencement de l'office et à l'Offertoire. Dans le rite d'accueil (point 10), la fonction de l'ārāti est de placer la cérémonie sous de bons auspices : une femme l'exerce à l'intention du prêtre, puis le prêtre l'exerce à l'intention des fidèles. Par rapport au texte qui stipule qu'une laïque présente au prêtre un récipient pour l'ablution de ses mains, ici, il s'agit d'un plateau contenant du vermillon et du santal dont la femme se sert pour marquer le front de l'officiant. À la séquence de l'Offertoire (point 12), l'ārâti traduit un geste de bénédiction, de salutation de la présence du Christ pendant le mystère de l'Eucharistie. Ce sont des jeunes filles qui l'exercent en utilisant des plateaux contenant chacun des fleurs, de l'encens, des cierges. Ces deux ārāti présentent un modèle original : ils sont assez proches de la forme sociale et s'écartent de la pratique religieuse hindoue, évitant ainsi la confusion.

En revanche, on observe une troisième pratique d'ārāti plus «hindouisée». Mise au point et pratiquée par les congrégations religieuses et les centres liturgiques et catéchistes indiens, elle est intégrée à la liturgie lorsque des prêtres indiens favorables à l'inculturation sont invités à célébrer une messe indienne au cours de leur passage aux Missions Étrangères à Paris (30). Le rite est pratiqué par le prêtre

(30) En 1998, c'est un prêtre indien du centre de catéchèse de Tindivanam qui a célébré la messe consacrée à la Vierge de Velankaṇni dans les jardins des MEP. Il a introduit la messe en soulignant que les rites expérimentaux présentés tout au long de la liturgie devraient être une source d'inspiration pour 
pour honorer la Bible ouverte sur l'ambon. Implicitement, il est destiné aux personnages bibliques. Sous cette forme, le rite s'écarte de la forme sociale et se rapproche de sa pratique dans le pūcai. Les opposants à l'inculturation en France ne s'y trompent pas en manifestant plus fermement leur désapprobation à son propos.

La messe annuelle honorant Notre-Dame de Velankanni de Pontoise est, de toutes les célébrations pondichériennes, la seule où les trois formes d'ārâti sont représentées. Le comportement et les discours des responsables de la "Communauté » ainsi que les innovations apportées chaque année à leur fête trahissent une volonté de se démarquer des autres. En effet, en la fondant, l'aumônier lui avait attribué le rôle de servir de communauté-modèle. C'est en s'appuyant sur les responsables de Pontoise qu'il a institué la "fête de l'amitié» uravu vila (31), qu'il a intégré les enfants dans la chorale afin d'aiguiser leur intérêt pour la langue tamoule, qu'il a introduit l'adoration du Saint-Sacrement dans la fête de la Vierge de Velankaṇni ou encore la pratique des trois formes d'ārāti. Depuis son départ, la fête de Pontoise s'est enrichie de quelques innovations qui ne relèvent pas de l'inculturation (32). Étant donné que la pratique des rites d'inculturation nécessite la participation des principaux membres de la "Communauté», une innovation comme un ajout d'un rite d'äräti est un moyen de se mettre davantage en scène et d'imposer sa suprématie aux autres «Communautés» pondichériennes. Dans le cas de Pontoise, l'objectif sous-jacent est de concurrencer la «Communauté» pondichérienne de Paris, une dimension que lui avait attribuée implicitement son aumônier en la créant et en la promouvant. Ainsi, les rites d'inculturation sont utilisés en tant qu'opérateurs d'altérité mais à un niveau différent du précédent. L' "autre» n'est plus la société chrétienne globale comme dans le cas des fêtes instituées par le prêtre paroissial ou par le diocèse (Fête des Migrants) car rares sont les personnes non tamoules qui participent à ces fêtes communautaires du fait de l'utilisation de la langue tamoule. L'altérité ici se joue entre une «Communauté» et les autres. Si cette altérité est pleinement exprimée à Pontoise, elle n'en existe pas moins au sein des autres «Communautés».

Cependant, l'introduction de nouveaux traits d'inculturation est limitée car une déviation trop audacieuse risquerait d'entraîner une forte désaffection des

\section{(suite de la note 30)}

augmenter l'inculturation des messes organisées par les Pondichériens de l'l̂le-de-France et valoriser la «culture indienne». En plus des trois types d'ärati, il a présenté une séquence rituelle assez troublante. Au moment de la prière universelle, tout en récitant $A U M$ śánti (sk) il a saisi un plateau contenant huit fleurs. Il a déposé les fleurs sur l'autel aux quatre points cardinaux, puis, aux points intermédiaires tout en évoquant le Christ sous ses différentes qualités à la manière de l'officiant hindou qui dépose des fleurs ou des pétales sur les divinités en énumérant leurs noms et leurs attributs avant de commencer l'arssanai arecanai et tout en ponctuant la séquence rituelle de $A U M$ śánti que les fidèles devaient répéter après lui. Ce rite trop «hindouisé » a suscité une grande confusion. À ma connaissance, aucune «Communauté » pondichérienne n'a osé l'introduire dans la liturgie de sa fête communautaire.

(31) La «fête de l'amitié» a été créée pour ressouder les liens entre les «Communautés» pondichériennes. Cette fête est organisée chaque année à tour de rôle par une "Communauté». Celle-ci prend en charge les frais de location de la salle et du repas, organise l'office religieux qu'elle anime par sa chorale et le spectacle auquel les autres «Communautés » sont conviées à présenter leurs propres créations de danse, de chant, ou de pièces de théâtre.

(32) Parmi ces innovations, on peut citer le cortège ecclésial à l'entrée de la messe précédé de la bannière de la «Communauté», la procession qui accompagne la Bible jusqu'à l'ambon, la représentation théâtralisée de l'hagiographie de la Vierge de Velankạ̣ni, le port de badges par les principaux membres de la «Communauté» qui permettent de les repérer dans leur qualité de donateur de la fête. 
Pondichériens pour ces fêtes. C'est déjà le cas pour de nombreux opposants à l'inculturation qui, de plus, n'acceptent pas que les organisateurs de chaque «Communauté» pondichérienne s'approprient l'exclusivité des marques de préséance. Ils appuient leur dissentiment en disant qu'il est inconvenant de transplanter le système hiérarchique indien en France, pays des Droits de l'homme par excellence.

C'est en partie par ces controverses que s'explique la faible participation des Pondichériens au pèlerinage officiel des Tamouls de France à Lourdes. Malgré la forte tradition pèlerine indienne et une profonde dévotion pour la Vierge de Lourdes (33), ce ne sont guère plus de 250 personnes qui participent à cet événement annuel, alors que pendant toute l'année, ils effectuent des visites au sanctuaire en famille (34). Ce pèlerinage a été fondé en 1989 par le délégué épiscopal des migrants du diocèse de Tarbes-Lourdes. Durant trois jours, les Pondichériens célèbrent des messes en tamoul dans les lieux les plus prestigieux du sanctuaire comme la Grotte ou la Basilique et détiennent le premier rôle dans une des processions mariales journalières ou dans celle du «corpus dei» et dans la messe internationale dominicale. De tous ces moments, la messe internationale est celui où la culture indienne est la plus «donnée à voir». Ces messes, célébrées dans l'immense basilique souterraine, ont des allures de représentation théâtrale grandiose dans laquelle se télescopent sans cesse les attitudes sacrées et profanes. L'introduction des groupes de pèlerins ainsi que leur départ à la fin de la cérémonie sont accompagnés des applaudissements de l'assistance, les Gloria entonnés pendant la prière universelle sont soulignés par des dizaines de petits drapeaux agités par les groupes de jeunes. La participation des Pondichériens provoque une séance supplémentaire d'ovations qui salue la prestation d'une jeune danseuse tamoule. En plus du rite d'āräti programmé au moment de l'Eucharistie, depuis quelques années, une présentation de danse părati natam a été incluse. Si depuis Vatican II, l'Église est devenue plus permissive vis-à-vis des expressions corporelles, celles-ci ne sont acceptables que dans la mesure où elles s'ancrent dans la tradition sociale et n'ont eu aucune fonction particulière dans une religion non-chrétienne. Bien que le părati natam soit perçu comme la danse indienne par excellence, on ne peut oublier qu'il était pratiqué (encore pratiqué dans certaines régions de l'Inde) exclusivement par les devadas $\bar{\iota}$, danseuses des temples et prostituées des prêtres. On comprend dès lors la controverse qu'une telle pratique déclenche. Les Pondichériens qui fréquentent le pèlerinage de Lourdes par dévotion sont extrêmement critiques sur l'exaltation de l'identité indienne à travers toutes ces manifestations et progressivement n’y participent plus. En revanche, les représentants des «Communautés » pondichériennes les plus revendicatives sont d'autant plus attirés par ce pèlerinage qu'il leur

(33) La Vierge de Lourdes, promue en Inde par les pères des MEP (un missionnaire du diocèse de Mysore, parent du père Peyramale, curé de Lourdes au moment des Apparitions, importa la première statue) et par les jésuites français, notamment pendant les épisodes cholériques, est présente aussi bien sur les autels domestiques que dans les édifices. Des églises sont placées sous sa protection comme celle de Villenur, important centre de pèlerinage à dix kilomètres de Pondichéry.

(34) Il convient de relativiser le phénomène, car, d'une part, les observations menées à Velankaṇịi et les constantes relevées dans les récits des Pondichériens et, d'autre part, la comparaison des pratiques pèlerines des Pondichériens et Sri Lankais tamouls à Lourdes montrent que les Pondichériens ont tendance à privilégier le pèlerinage familial au détriment du collectif. Cet aspect s'accentue en France sous l'influence de la culture globale individualiste. 
offre une occasion de se mettre en valeur et d'asseoir leur pouvoir (35). Hier, c'étaient les représentants de la «Communauté» de Paris qui dominaient le pèlerinage, aujourd'hui ce sont ceux de Pontoise et il est difficile d'ignorer les prétentions de deux familles pondichériennes de Paris et d'Évry-Grigny à prendre la place des représentants de Pontoise. Les Pondichériens venus de la province ne connaissent pas cette hiérarchisation propre aux «Communautés» de l'Île-de-France. Subissant la domination des "Communautés» franciliennes, certains groupes importants, comme celui du sud-est de la France, constitués essentiellement d'intouchables, ne se joignent à eux que pour les temps liturgiques. Pour l'hébergement, ils ont choisi un quartier très éloigné de celui des Franciliens afin de limiter les rencontres.

\section{Conclusion}

L'impression qui domine ce dossier est celle d'un décalage, d'un malentendu entre une volonté ecclésiale et les désirs des Indiens. Comme au temps des missionnaires, la communauté catholique indienne se montre toujours aussi capricieuse et difficile à gérer. Quand l'Église au XVIII e siècle interdit les pratiques jugées superstitieuses ou hindoues (36), les catholiques résistent et leur résistance est si forte que certaines des coutumes ont traversé les frontières du temps et de l'espace. On pense au $\overline{t a l i}(37)$, bijou que la jeune femme reçoit le jour de ses noces. Aujourd'hui, le prêtre bénit le tăli comme s'il s'agissait d'un anneau nuptial et il en est ainsi en France dans les mariages intracommunautaires comme dans les mariages mixtes. On pense aussi à la fête de nubilité que les missionnaires jésuites ont essayé d'associer à la cérémonie du mariage (38). Cette cérémonie est toujours pratiquée dans la sphère domestique en l'absence d'un prêtre. Le rite de nubilité s'est aussi exporté en France. Les Tamouls des DOM et de Pondichéry qu'ils soient hindous, chré-

(35) Lorsque j'ai assisté à ce pèlerinage en 1999, seules les trois «Communautés» de Paris, Pontoise et Évry-Grigny étaient présentes. Il faut noter que la «Communauté » de Paris était très faiblement représentée, son responsable, très critiqué pour son hégémonie, n'apparaissant plus à Lourdes. En son temps, c'était la bannière de la «Communauté» de Paris qui flottait dans le ciel de Lourdes, aujourd'hui, c'est celle de Pontoise.

(36) Référence à la bulle Omnium solicitidinum de Grégoire XIX qui a mis fin à « la Querelle des Rites Malabars» en statuant chaque «doute», c'est-à-dire chaque rite autorisé par les jésuites dans le cadre d'une accommodation du christianisme en Inde et dénoncé par les capucins. (Bullarium Benedicti $X I V$; trad. SÉBAstia, 1999, app. III, pp. 204-205).

(37) Le $\overline{t a} l i$ est un pendentif portant le symbole de Ganeśa (ou de Viṣnu) monté sur une cordelette composée de 108 fils jaunis à l'eau teintée de curcuma. Le nombre de fils traduisant un chiffre sacré hindou, l'emploi du curcuma ainsi que le symbole inscrit sur le bijou furent considérés comme des expressions de la superstition. Les jésuites avaient accepté l'emploi chez les catholiques en substituant la croix ou une effigie de la Vierge au symbole du dieu hindou. C'est sous cette forme qu'il s'est perpétué jusqu'à maintenant.

(38) Lorsque les mariages étaient arrangés dès l'enfance, la fête de nubilité marquait le moment où la vie de couple pouvait commencer. Avec l'interdiction des mariages d'enfants non pubères, la fête de nubilité consista à présenter la jeune fille en vue de chercher ou de sceller des alliances préférentielles ou non. 
tiens, ou même musulmans ne manquent pas de le célébrer car il permet d'élargir le cercle des relations pourvoyeuses de futures alliances. Quand au moment de la décolonisation, l'Église révise ses positions quant à l'importance d'indigéniser le catholicisme dans les cultures non chrétiennes et accorde aux catholiques la possibilité de pratiquer des rites selon leur sensibilité, ici encore, c'est une résistance qui s'élève :

«Si on est devenu chrétien, ce n'est pas pour faire la même chose que l'on faisait lorsqu'on était hindou.» (un fidèle intouchable rencontré au cours de la messe de l'Assomption à Nellitope (célébration inculturée)

Il convient de souligner qu'une grande partie des catholiques appartient aux castes inférieures. La conversion était souvent un moyen d'échapper à la discrimination exercée par les castes supérieures pour les maintenir dans l'ignorance et la servitude. Hindous, ils ne pouvaient ni pénétrer dans un temple brahmanique ni recevoir les services de l'officiant, alors qu'en devenant catholiques, ils avaient accès aux églises et aux prêtres. Bien sûr, les «bonnes castes» converties ont maintenu une forte ségrégation à l'égard des intouchables, les obligeant à se tenir dans un espace circonscrit de l'église et à recevoir la communion séparément, à se faire administrer par un clergé spécifique et à respecter la distance sociale dans leur vie quotidienne. Néanmoins, dans certaines conditions, des intouchables ont réussi à bénéficier d'un meilleur statut, impensable s'ils étaient restés hindous (Mosse, 1986; Hardgrave, 1969). Certains usages discriminatoires au sein de l'Église ont fini par s'assouplir ou disparaître, mais la ségrégation est toujours là, reproduite par le comportement du clergé indigène ou par la pression des «bonnes castes» qui n'entendent pas se laisser dépouiller de leurs privilèges.

Pour les catholiques intouchables, affirmer une identité chrétienne signifie rejeter tout ce qui symbolise l'hindouisme. Bien que leurs comportements et leurs coutumes dénotent une forte intériorisation des conceptions hindoues, ils condamnent le modèle hiérarchique qui les stigmatise et les pratiques religieuses jugées «superstitieuses». C'est une manière de se targuer d'appartenir à une religion plus évoluée, égalitaire et fraternelle. Les travaux sur l'inculturation restent également trop intellectuels ou trop abstraits pour qu'ils se sentent concernés. Les modèles dont ils s'inspirent, puisent dans la littérature savante brahmanique ou dans les mouvements spirituels hindous (Fédou, 1998; Clémentin-Ojha, 1993; Jayakumar, 1999) du fait même qu'ils émanent d'une minorité de religieux appartenant souvent aux castes supérieures, plus soucieux de déstigmatiser l'Eglise de ses accents coloniaux en lui insufflant des connotations hindoues que de répondre au réel besoin de la communauté catholique. Toujours considéré comme une religion d'origine occidentale, le catholicisme indien doit se construire une identité «authentiquement indienne». Il en va de sa survie car de nombreux facteurs entravent son expansion tels que l'exclusion des basses castes chrétiennes des quotas de réservation institués par l'État indien pour amoindrir les différences économiques, les agressions antichrétiennes organisées par les mouvements fondamentalistes, le comportement du clergé indigène trop distant et élitiste. Si les traits d'inculturation rencontrent peu la faveur des intouchables, ils n'exercent qu'un attrait relatif auprès des castes supérieures et du clergé paroissial. Ces derniers justifient leur refus par l'intérêt de conserver intégralement l'identité catholique qui reflète les valeurs civilisatrices propres à l'Occident. On remarque à ce niveau, que si les promoteurs de l'inculturation se qualifient de «modernistes» par rapport aux opposants pensés en terme de 
«traditionnalistes», la manipulation des qualificatifs est implicitement inversée dans le discours des opposants. Ces derniers considèrent les traits d'inculturation comme des réminiscences de gestes superstitieux et leurs usages signent un retour à l'«archaïsme» hindou.

Si les efforts développés par Vatican II en faveur de l'inculturation n'ont pas abouti en Inde, ceux favorisant l'expression de la culture des migrants ont été détournés de leurs objectifs par les Pondichériens de France. L'aumônerie, créée pour répondre au besoin spirituel et moral de toute la communauté tamoule, n'a en charge aujourd'hui qu'une petite minorité de Pondichériens. Les Sri Lankais ont été évincés et une importante partie de la communauté préfère ne pas la fréquenter afin d'éviter les conflits de pouvoir et les attitudes discriminatoires. Certaines fêtes mariales (Paris, Pontoise) attirent de nombreux Pondichériens, mais les attitudes d'évitement, de distance, trahissent que la participation est motivée par la dévotion et non par la rencontre des compatriotes. En France, les traits d'inculturation rencontrent également une forte désapprobation. Les opposants de toutes castes refusent que l'Église serve de lieu d'exaltation à l'identité tamoule. Ils considèrent que les pratiques religieuses des Pondichériens doivent se calquer sur le modèle français car celui-ci respecte les valeurs d'égalité et de fraternité inhérentes à l'Église comme à la nation française, alors que l' «indianisation» du registre religieux induit les valeurs pernicieuses du système hindou. Les intouchables, qui ont bénéficié d'indéniables avantages dont ils seraient privés s'ils étaient en Inde, n'ont guère envie de voir resurgir la discrimination. Les membres des «bonnes castes», souvent des personnes qui ont fait des études supérieures en France et qui ont fortement intériorisé le modèle culturel français, réduisent les contacts avec leur communauté. Elles ne participent pas aux fêtes organisées par leur communauté et préfèrent se joindre aux activités de leur propre paroisse.

L’Église qui, idéologiquement, s'oppose à la politique française en matière d'immigration, connaît également de grandes difficultés pour créer une véritable fraternité entre les communautés catholiques de cultures différentes. En permettant aux migrants de s'exprimer dans leur langue maternelle et en insistant sur l'importance de la conservation des cultures, elle prend le risque d'accentuer le phénomène de «ghettoïsation». C'est ce que l'on peut observer dans le comportement des Portugais ou des Pondichériens. Ces derniers n'hésitent pas, d'ailleurs, à appuyer leurs demandes d'installation d'une Vierge de Velankaṇni ou d'une messe communautaire auprès du curé paroissial en citant les Vierges de Fatima ou les célébrations portugaises en exemple. Cependant, il convient de préciser que le développement d'une religiosité communautaire apporte une aide indéniable aux migrants, et plus précisément aux Pondichériens, qui doivent faire face aux nombreuses difficultés dues à l'important décalage culturel entre leur pays d'origine et la France.

Si on a pu mettre en évidence l'importance de l'encadrement institutionnel dans le développement des activités religieuses des Pondichériens catholiques, il convient néanmoins de souligner que celui-ci n'aurait pu être aussi opérant sans l'intervention de facteurs qui ont induit une prise de conscience identitaire. Le premier fait significatif est la confrontation des Pondichériens à une communauté sri lankaise de plus en plus «visible». Les Pondichériens qui, par leurs emplois dans l'administration française, se pensaient bien intégrés («bons français et bon chrétien»), se sont vus progressivement assimilés aux Tamouls du Sri Lanka du fait de 
leur ressemblance physique et de leur langue. De plus, ils ont subi (et subissent encore) les critiques des Sri Lankais qui leur reprochaient un parler tamoul corrompu (39), leur manque de dynamisme économique et leur désintérêt pour la culture tamoule. Ces railleries ainsi que la visibilité qu'ils ne pouvaient plus renier ont induit une réaction positive vis-à-vis des critères culturels. Cette émergence d'une conscience identitaire trouvait d'autant plus d'aisance à s'exprimer que la France, à l'image de l'Occident, était fascinée par la culture indienne qui reflétait l'exotisme, le mysticisme et la teneur philosophique des religions orientales. Le second critère important dans la valorisation de la culture tamoule a été la question de l'acculturation de l'éducation des enfants. Ce sont une fois de plus les Sri Lankais qui ont fait prendre conscience aux Pondichériens de leur désengagement dans la transmission des valeurs culturelles. Il est vrai qu'aujourd'hui l'usage du bilinguisme chez les enfants est bien accepté alors qu'auparavant l'emploi de la langue maternelle était perçu par les instituteurs comme un obstacle à l'apprentissage de la langue française. De ce fait, de nombreux jeunes Pondichériens parlent peu ou pas tamoul, ne le lisent pas et ne l'écrivent pas. Cette ignorance à l'égard de la langue est aujourd'hui vécue comme un handicap pour maintenir les liens familiaux ou affectifs avec Pondichéry et les jeunes parents engagent de plus en plus leurs enfants à apprendre la langue auprès des grands-parents ou d'associations tamoules. Certains Pondichériens justifient l'emploi de la langue tamoule et l'introduction de traits culturels au sein des fêtes communautaires dont ils sont promoteurs, comme un moyen d'intéresser les enfants aux valeurs de leur culture d'origine. À ce niveau, les activités religieuses menées au sein de l'Église catholique possèdent une fonction supplémentaire, celle de socialiser les enfants dans une conscience identitaire.

\author{
Brigitte SÉBASTIA \\ Centre d'anthropologie de Toulouse
}

(39) Les critiques des Tamouls sri lankais à l'égard de la langue parlée au Tamil Nadu porte sur l'important usage de l'anglais : «Les mouvements dravidiens ont banni le sanskrit de la langue tamoule mais, dans les faits, les mots sanskrits ont été remplacés par des mots anglais ». 


\section{BIBLIOGRAPHIE}

AMALORPAVADASS D.S., Towards Indigenation in the Liturgy. Bangalore, National, biblical, catechetical and liturgical centre, 'Mission theology for our times series $n^{\circ} 6$ ', non daté.

Benedicti XIV Bullarium, MDCCCXLV, Aldina, Prati in typographia, pp. 421-434 (1ère éd. MDCCXLVI).

BERTRAND Père, S.J., La mission du Maduré, Paris, Poussielgue-Rusand, 4 vol., 1848.

BOURDAT Pierre, Pondichéry XVIII . Pondichéry, Musée de Pondichéry, 1995.

CLÉMENTIN-OJHA Catherine, «Indianisation et enracinement: les enjeux de 1''inculturation' de l'Église en Inde. », Bulletin de l'EFEO, 80-1,1993, pp. 107-133.

CLÉMENTIN-OHJA Catherine, «L'indigénation du christianisme en Inde pendant la période coloniale (1498-1947)», Archives de Sciences sociales des Religions, 103, 1998, pp. 5-19.

COMARMOND Jean-Marc de, «La communauté française de Pondichéry: 1'oubli et l'espérance», L'Afrique et l'Asie modernes, CHEAM, $\mathrm{n}^{\circ} 146$, automne 1985, pp. 3-19.

Concile œcuménique Vatican II. Constitutions, décrets, Déclarations. Paris, Éditions du Centurion, 1967, notamment les Constitutions «Lumen Gentium» pp. 13-122; «Sacrosanctum Concilium» pp.149-205; «Gaudium et Spes» pp. 209-348; «Ad Gentes divinitus» pp. 539-602.

COUTURE André, «La tradition et la rencontre de l'autre», in Frédéric LENOIR et Y. T. MASQUELIER, éds., Encyclopédie des religions, Paris, Bayard, 1997.

DELIÈGE Robert, Les Paraiyars du Tamil Nadu, Nettetal Steyler Verlag, Studia Instituti Anthropos, 1988.

DIRKS Nicholas B., "The conversion of caste: location, translation and appropriation", in P. VAN DEER VEER, ed., Conversion to Modernities: the Globalization of Chritianity, Londres, Routledge, 1996, pp. 115-136.

Documentation catholique, 1145, 19 avril 1953, «Actes du Saint-Siège. Constitution apostolique « exsul familia» sur l'aumônerie des migrants», pp. 455-502.

Documentation catholique, 1398, 21 avril 1963, «Encyclique 'Pacem in terris' de S.S. Jean XXIII sur la paix entre toutes les nations, fondée sur la vérité, la justice, la charité, la liberté», pp. 513-546.

Documentation catholique, 1555, 18 janvier 1970, «Motu proprio de S.S. Paul VI promulguant les nouvelles normes sur la pastorale des migrants », pp. 58-94.

Documentation Catholique, 1556, 1er février 1970, 133- 137, «Pour une liturgie mieux adaptée aux traditions indiennes »

Documentation catholique, 1642, 18 novembre 1973, «La pastorale des migrants. Théologie de l'Église particulière par rapport au fait migratoire. Rapport de Mgr Alfred Ancel, évêque auxiliaire de Lyon à la rencontre européenne sur la pastorale des migrants », pp. 962-974.

Documentation catholique, 1906, 17 novembre 1985, «L'intégration des émigrés dans la société et dans l'Église. Discours au $2^{\mathrm{e}}$ Congrès mondial de pastorale de l'émigration », pp. 1054-1055.

Documents Épiscopat, 6, mars 1987, «Au service de la catholicité de l'Église. Les aumôneries ethniques dans la Pastorale des Migrants », pp. 1-12.

DUMONT Louis, Une sous-caste de l'Inde du Sud. Organisation sociale et religion des Pramallai Kallar, Paris-La Hague, Mouton, 1957 (Paris, EHESS, 1992).

FEDOU Michel, Regards asiatiques sur le Christ, Paris, Desclée, 1998, «Jésus et Jésus Christ 77 ».

GERWIN VAN LEEUWEN J. A. G., O.F.M. Fully Indian Anthentically Christian, Bangalore, National Biblical Catechetical and Liturgical Centre, 1990.

GOOD Anthony, «A symbolic type and its transformations. The case of South Indian Ponkal», Contributions to Indian Sociology, 17-2, 1983, pp. 221-244.

HARDGRAVE Robert L., The Dravidian Movement, Bombay, Popular Prakashan, 1965.

HARDGRAVE Robert L., The Nadars of Tamilnad. The political Culture of a Community in Change, Berkeley-Los Angeles, University of California Press, 1969.

JAYAKUMAR Samuel, Dalit Consciousness and Christian Conversion. Historical Resources for a Contemporary Debate, Delhi, ISPCK, 1999.

LAUNAY Adrien, Histoire des missions de l'Inde. Pondichéry, Maïssour, Coümbatour, Paris, Ancienne maison Charles Douniol, 4 vol., 1898. 
La documentation catholique, 2190, 18 octobre 1998, «L'immigration, défis et richesses. Conclusions des Semaines sociales de France 1997 », pp. 885-890.

LEGRAND Lucien, «Inculturation. Quelques points de repère bibliques. », Bulletin de documentation des Missions étrangères, 279, mai 1993, pp.133-141.

Lettres des Nouvelles Missions du Maduré, Lyon, Imprimerie Louis Perrin, tome I, 1839, tome II, 1840, tome III, 1843, tome IV, 1847.

MILES Williams F.S., Imperial burdens. Countercolonialism in Former French India. Colorado, Lynne Rienner Publishers, 1995.

MOSSE C. David F., Caste, Christianity and Hinduism: A Study of Social Organization and Religion in Rural Ramnad, Oxford, University of Oxford, Institute of Social Anthropology, D. Phil thesis, 1986.

MOUDIAPPANADIN Joseph, «Tamouls, une communauté plurielle », Accueillir, 191, juillet-août 1993, pp. 26-27.

NEOGY Ajit, K., Decolonisation of French India. Liberal Movement and Indo-French Relations 1947-1954, Pondichéry, Institut Français de Pondichéry, 1997.

NOBILI Roberto de, Première apologie, 1610, Paris, Éditions Spes, 1931 (texte inédit latin traduit et annoté par le P. Pierre Dahmen, s.j.), (coll. «Bibliothèque des missions Mémoires et Documents ».

NORBERT R. P., Missions historiques. Présentées au Souverain Pontife Benoit XIV sur les missions des Indes Orientales. Mémoires historiques sur les missions des Malabar, Luques, tome II, 1764.

PUTHANANGANY Paul, «Inculturation de la liturgie en Inde depuis Vatican II », Concilium 'Une tradition créatrice', 182, 1983, pp.115-124.

SÉBASTIA, Brigitte, Caste et christianisme à Vailankanni. Étude historique, sociale et religieuse d'un sanctuaire marial au Tamil Nadu. Mémoire en vue du diplôme de l'EHESS, Toulouse, 1998.

WEBER Jacques, Pondichéry et les comptoirs de l'Inde après Duplex. La démocratie au pays des castes, Paris, Denoël, 1996, (coll. «Destins croisés»).

XAVIER Johannes-Bernard, «Une prière eucharistique pour 1'Inde. », Bulletin de documentation des Missions étrangères, 285, janvier 1994, pp. 25-30.

ZUPANOV Ines G., Disputed Mission. Jesuit Experiments and Brahmanical Knowledge in SeventeethCentury India. New Delhi, Oxford University Press, 1999. 


\section{Résumé}

Confrontée au double mouvement de décolonisation et de migration, l'Église, depuis le second concile du Vatican, s'est donnée les priorités de favoriser l'intégration des communautés catholiques au sein de leur propre culture (niveau indigène), et de favoriser l'intégration des différentes communautés catholiques migrantes au sein des pays d'accueil (niveau exogène). L'article traite de ces questions à travers le cas de l'Inde et de la communauté pondichérienne installée en Île-de-France. Les exemples présentés démontrent un important décalage entre les perspectives ecclésiales et ses applications. L'élite cléricale indienne, invitée à réfléchir sur les moyens d'"inculturer" le catholicisme en tenant compte de la sensibilité indienne, se montre plus soucieuse de créer une "Église authentiquement indienne" qu'à répondre aux besoins réels de sa communauté. Aussi, les traits d'inculturation qu'elle introduit dans la liturgie ne sont guère pratiqués en Inde du fait de leur connotation hindoue. En revanche, ils suscitent un vif intérêt auprès des Pondichériens de France qui les considèrent comme des marqueurs de l'identité indienne. Ils apparaissent dans les messes tamoules dès lors que les Pondichériens sont dotés d'un aumônier tamoul ou lorsqu'ils sont invités à présenter devant la communauté paroissiale, une messe selon la coutume du pays. Les objectifs ecclésiaux visent l'intégration des communautés culturellement plurielles au sein de la grande famille catholique, mais la présence d'aumôniers tamouls a favorisé l'expression d'un catholicisme "à l'indienne» marqué par les jeux de pouvoir basés sur des critères indiens (caste; statut économique) ou français (grade militaire). Ces rivalités ont provoqué l'éclatement de la communauté en six groupes qui se font mutuellement concurrence. Cette émulation apparaît nettement à travers les innovations ou l'ajout d'un rite d'inculturation dans certaines messes annuelles organisées par les "Communautés » qui possèdent une statue de la Vierge de Velankanni (Vierge apparue au Tamil Nadu) dans leur paroisse. Dans ce cas, les traits d'inculturation fonctionnent comme des marqueurs d'altérité.

\section{Abstract}

Confronted with the movements of decolonization and immigration, since Second Vatican Council, Roman Catholic Church has been careful to integrate mission countries's catholic communities into their own culture (indigenous level) and to integrate various catholic migrants into the western countries (exogenous level). This article examines these perspectives through the cases of India and the Pondecherrian communities near Paris. These articles point to an important discrepancy between the aims of the Church and the way in which the local Churches have applied them. Invited by Roma to introduce some modifications in the catholic liturgy according to the indian sensibility, the elite Indian clergy shows more interest in creating an authentically Indian Church than meeting the needs of the community. Thus, the inculturation rites introduced in the liturgy are hardly practiced in India because of Hindu connotations. They interest greatly the Pondecherrians in France however because they express Indian identity. They appear in the Tamil mass when the Pondecherrian community got a Tamil chaplain and were invited by the parish priest to present a mass performed according Indian custom; If the goals of the Church point out the integration of the culturally various communities inside the Catholic family, Tamil chaplains have encouraged a Catholicism «à l'indienne» with the expressions of rivalry and emulation based on Indian criteria (caste, economic status) and French ones (military rank). They provoked also the scission into six distinct communities which compete with each other. This emulation appears clearly through the innovations and additions of inculturation rites into annual services organized by communities who possessed a statue of the Virgin of Velankanni, a Virgin who appeared in Tamil Nadu in the seventeenth century. Then, the performance of the inculturation rites acts as a mark of ethnicity. 


\section{Resumen}

Favorecer la integración de las comunidades católicas en el seno de su propia cultura (nivel indígeno) y favorecer la integración de las distintas comunidades católicas emigrantes dentro de los países de acogida (nivel exógeno) son las prioridades que se ha dado la Iglesia, confrontada al doble movimiento de decolonización y de migración, desde el segundo concilio del Vaticano. El presente artículo trata de dichas cuestiones mediante el caso de la India y de la comunidad procedente de Pondichéry e instalada en París (capital y afueras). Los ejemplos presentatos demuestran un importante desajuste entre las perspectivas eclesiales y sus aplicaciones. La élite clerical india, a la que se le ha propuesto reflexionar sobre los medios de "inculturar" el catolicismo tomando en cuenta la sensibilidad india, manifiesta un cuidado más especial a la hora de crear una "Iglesia auténticamente india" que para responder a las necesidades reales de su propia comunidad. Por lo tanto, los rasgos de inculturación que introduce en la liturgia no son de los más praticados en la India debido a su conotación hindú. En cambio, dichos rasgos les llaman mucho la atención a los nativos de Pondichéry establecidos en Francia porque los consideran como unos distintivos de la identidad india. Durante las misas tamules, están presentes en cuanto los nativos de Pondichéry disponen de un capellán tamul o cuando se les invita a que presenten ante los feligreses una misa de acuerdo con la costumbre de su pais. Los objectivos eclesiales no buscan sino la integración de las communidades, plurales a nivel cultural, dentro de la gran familia católica pero la presencia de capellanes tamules han favorecido la expresión de un catolicismo "a lo indio" señalado por los juegos de poder basados en criterios indios (casta; estatuto económico) o francés (grado militar). Dichas luchas provocaron la fragmentación de la comunidad en seis grupos que rivalizan entre sí. Esta emulación aparece claramente a través de las inocaciones o de la añadidura de un rito de inculturación en algunas de las misas celebradas anualmente $y$ organizadas por las "Comunidades" que poseen una estatua de la Virgen de Velankanni (una Virgen que apareció en Tamil Nadu) en su parroquia. En este caso, los rasgos de inculturación no funcionan sino como distintivos de alteridad. 